\title{
Farnesyl Transferase Inhibitor
}

National Cancer Institute

\section{Source}

National Cancer Institute. Farnesyl Transferase Inhibitor. NCI Thesaurus. Code C2020.

Any substance that inhibits protein farnesyltransferase, an enzyme that catalyzes the transfer of a farnesyl moiety from farnesyl pyrophosphate to a cysteine. Protein farnesyltransferase is involved in Ras-mediated post-translational modification. Inhibition of protein farnesyltransferase may inhibit the oncogenic activity of Ras. 